\title{
Research on Tempting Investigation legality
}

\author{
Kangqing Wang \\ People's Public Security University of China, Beijing 100038, China. \\ 1033063525@qq.com
}

\begin{abstract}
Temptation Investigation in criminal proceedings as a special investigative techniques, in practice plays an irreplaceable role, but its legitimacy is a question worth exploring. In fact, the substance only grasp and understand the temptation investigation of the legality of the investigation in order to lure a thorough analysis, the premise is to clarify the legality of the analysis the connotation of "law", and on the basis of substantive law and procedural law from two dimensions legality analyzed in order to demonstrate their deep legal connotation.
\end{abstract}

Keywords: Police entrapment; opportunities offered; mens rea induced; legal.

\section{Introduction}

With the progress and development of society, the complexity and the increasing crime intelligence, temptation investigation as a special investigative techniques in the organization of strong, high intelligence, good concealment crime is frequently applicable, however, to academia its legitimacy issue has been analyzed from multiple perspectives, it should be how to grasp and understand the thought-provoking work in practice.

\section{Concept}

\subsection{The Concept of Investigation.}

In accordance with the narrow understanding, "Investigation" is a legal act in criminal proceedings, there is no illegal investigation, he said it therefore investigate temptation investigation is legal does not make sense; in accordance with the broad sense, the investigation is only a function of behavior, both public investigative activities, including secret investigative techniques (ie, reconnaissance), either legally or may be illegal, based on this article discusses the legality of temptation investigation in a broad sense.

\subsection{Temptation Investigation, Stimulate Investigation, Detection Trap, Trap Investigation Concept.}

Investigation trap, trap investigation fundamental concept is the same in English as entrapment, mean / investigating authorities would have no criminal tendencies in the innocent heart implant (implant) Criminal intent, criminal acts to induce its implementation and then allowed to be prosecuted. US Department of Justice in May 1981 on the base of the secret investigation 6 (Attorney General. S Guidelines on FBI Undercover Operations) of the $\mathbf{J}$ key also is the temptation to think that entrapment or encouraging others to illegal means, and should be avoided whenever possible. Clearly, the United States snare or trap is a negative attitude.

Temptation investigation, the investigation stimulate the connotation and extension are basically the same, the English as encouragement, to some extent, the United States it is recognized.

Temptation investigation is also known to stimulate the investigation, in terms of its extension covers the investigation trap (trap investigation), we can say the investigation is stuck in a sense of temptation investigation.

\subsection{Concepts of Enticement Investigation.}

Currently Entrapment generally have the following meaning several views: the first refers to the criminal investigation personnel to implement an action profitable as bait to lure the investigation implied or objects exposed their criminal intent and criminal acts to be criminal acts performed 
results arrest occurred or be tempted by ; second, the temptation investigation (police encouragement), refers to the state investigation authority for those who have criminal intent who, in order to obtain evidence to institute criminal proceedings and to induce their criminal acts, when he really was induced to commit a crime, to be arrested on the spot a legitimate investigative behavior. The third refers to the major complex hidden criminal cases, there is evidence in the suspects have criminal intent or criminal tendencies conditions, investigators in strict accordance with the provisions of the law for criminal suspects to provide opportunities and conditions, when a crime or let it self-exposure on the spot will be caught red-handed one other special investigative techniques . Although several definitions of different forms, but careful workmanship, the definition of the characteristics are the following aspects: the specificity of (1) the implementation of the case: having hidden, no victim, there are cases of large hazardous; $(2)$ the police have the initiative, according to the specific circumstances of the case the initiative to implement the temptation investigation; (3) to any temptation investigation of investigative techniques, the implementation of the temptation investigation is voluntary and not with the relative person rights and interests of the people opposing mandatory result hurt.

\section{Analysis of Enticement Investigation legitimacy}

\subsection{Type and Temptation Investigation Sort.}

Correct Understanding of Types and Classification criteria temptation investigation, for us to correctly understand the temptation of investigating the legality of great significance.

According to the suspect's subjective and objective, specifically from the temptation investigation of the role of objects, is the behavior of the intensity of the temptation of the subjective aspects of the investigation were three specific classification based on the point of view, can be temptation investigation into two types: the first type is the Criminal intent induced refers seducer seducer was prompted originally generated and there is no criminal intent their criminal acts, such as the United States in 1932 Suole Si violation of Prohibition Act and the 1958 Sherman provide drug cases; second is the opportunity to provide type it refers to the temptation to provide a conducive already been generated objective conditions and opportunities for criminal intent or that you have a previous criminal acts of those who are tempted to carry out criminal acts such as the Russell 1973 US manufacturing, trafficking in narcotics and narcotics trafficking in 1976, Hampton.

\subsection{Legitimacy of "Law".}

In China, by far the law has not yet made provisions relating to the temptation investigation, if just from the narrow perspective of "law" to understand, then, from the limitations and hysteresis of the statute of view, then, we have adopted trap investigation. unlawful behavior, then we are here to discuss the temptation investigation would not make any sense, but I think from the "law" of the generalized angle and the actual investigation entice investigation in combating such as drug trafficking, prostitution, cybercrime, counterfeiting of currency and bribery etc., has a hidden, no victims of crime have a greater harm in huge and irreplaceable role to understand and investigate the legality of the temptation investigation will give us the actual investigation and to provide complete legal little useful reference.

\subsection{From the Analysis of the Substantive Law.}

Analysis of the Criminal intent induced type Enticement Investigation.

Body: generally enjoy the right of investigation investigative personnel, subject appropriate.

Object: Criminal intent induced type of temptation investigation against the object is not a specific person, this crime against targeted criminals and expose the investigating authorities to combat and suppress primary responsibility is completely contrary to this perspective, investigators in the "teaching" crime, its temptation to act itself is a crime.

Subjective: from a subjective perspective, investigative organs to implement the alluring temptation investigation often for a variety of purposes, some may be through a set of clients arrest 
internship fine revenue, and some may be out of politics fight against others, subjective seducer of suspected intentional crime

Objective: to implement investigative organs seductive investigation objectively not only can not play a role in the fight against crime, educate the masses, so that people may also lose the legal fairness, justice, faith, damage people's trust in government and support, seduction the investigation itself will be harmful to society often to be tempted by its own crime.

For the opportunity to provide the type of temptation investigation analysis.

Body: generally enjoy the right of investigation investigative personnel, subject appropriate.

Object: Object type temptation investigation the opportunity to provide targeted general have had a previous independent criminal acts, mostly in premeditated stage is the investigating authorities to have a certain clue specific suspects.

Subjective: Actually before the temptation to be seduced by the temptation of those embodiments, the tempter has produced criminal tendencies or have a previous criminal behavior, subjective seducer just want to provide an opportunity for the already produced Criminal intent be seduced by its exposure to crime only, therefore, the opportunity to provide the temptation to type the subjective aspect is legal

Objective: to provide the opportunity to type because temptation investigation and arrest of criminals in general have had a previous criminal acts independently, even be tempted to look at the crime, its initiative also rests in the hands of criminals, he can be free of its will decide whether criminal behavior and in what manner to carry out criminal acts, the tempter can not afford to participate in a leading role in the whole case, but only to provide a favorable opportunity. If there is no suspect's behavior, the behavior of the temptation to provide opportunities no substantial harm.

So, just from the point of view of substantive law, when Criminal intent induced type of temptation investigation illegal, it should be prohibited, and the opportunity to provide a stronger type of temptation investigation legitimacy, by setting the appropriate rules in the law to be included in the normal using channels.

\section{Conclusion}

(1). Different types of criminal investigation. To trap investigation has a comprehensive inquiry will temporarily put aside the provisions of the law of our country, but no legal research on this issue, we must first understand the different types of countries in criminal investigations, there are several types specifically : A. after the investigation type, at present China's "Criminal Procedure" with this type; B. preliminary investigation and formal investigation bound; C. even if the formal investigation type; D. immediate formal investigation type.

(2). Analysis of the Criminal intent induced type Enticement Investigation. Criminal intent induced type of temptation investigation often out after the first "investigation" poor filing procedures for the purpose of a specific person is not taken to induce others to produce Criminal intent and criminal, from the procedural law is concerned, the program suspected illegal heavier.

(3). For the opportunity to provide analytic Enticement Investigation. Type temptation investigation the opportunity to provide general are mostly looking for suspects in the process, and in most cases there are clues to specific people and open, basically is the first occurrence of the case, then start filing investigative procedure, and be tempted by the majority for criminal suspects, from the procedural point of view, it is basically in line with provisions of the law; of course, in practice there will be some promise exceptions, especially in the case of an emergency actions taken, but also to prevent crime further to others, resulting in greater social harm, and the behavior forced to take, although there are procedural violations of the suspects, but the overall advantages and disadvantages in terms of reducing the harm for, from a legal point of view, it should be by law Inclusive.

(4). Type temptation investigation the opportunity to provide trends in the law. Based on the above analysis, we can clearly see the essence of the legal procedures established primarily to ensure the realization of substantive justice, when the procedural law if they can do that of course is good, but it can not do this that even hindered the realization of substantive justice, then it should do the necessary 
and appropriate modification, at present, after the investigation of the pattern in response to today's increasingly sophisticated criminal means, hidden dangers of the growing increase era, a more timely manner to combat crime and protect the public interest, immediate investigation of urgency more apparent, so I appeal to our investigation procedure should be used is: the preliminary investigations and the formal investigation combined. Providing opportunistic temptation investigation should be in line with the development trend of the Criminal Procedure Law.

\section{References}

[1] Lawsuits, Sunxiao Fu. Temptation Investigation. Law and Business Research, 2001 (4).

[2] Sorrellsv. U.S., 287 U.S. 435, 53 S.Ct. 210, 77 L. Ed. 413 (1932) .See JeroldH. Israel and Wayne R. Lafave, Criminal Procedure, West Group 1993,5th ed, p.174.

[3] Long Zongzhi temptation investigation of the legality of .M. People's Justice, 2000 (5).

[4] Danhong, Sunxiao Fu. Tempting Investigation. Law and Business Research, 2001 (4).

[5] Chen rights. Procedure Law Police Entrapment. Chinese Journal of Criminal Law, 2004 (2).

[6] Lawsuits, Sunxiao Fu. Tempting Investigation. Law and Business Research, 2001 (4). 